\title{
Thinking through Signs: The Ayah Zeitgeist
}

\author{
Elma Berisha*
}

Imagine you are living in a seventh-century desert town and a new book, which is not even a 'book' yet, is being recited in scattered verses, urging ordinary people to look around for 'signs'. What would one see in that sky-is-blue earthis-flat age if one had attentively and eagerly looked around? "Then, do they not look at what is before them and what is behind them of the heaven and earth?... Indeed in that is a sign..." (Q.34:9). How to respond to this invitation to probe for signs when there are no telescopes or microscopes available? You would have looked up at the stars unaware that many of them were galaxies. You would have looked at your hands, observed their skin, but without a way to know that it is made up of highly-specialised cells composed of extraordinarily complex and coordinated sub-cellar organelles. To discern signs "in your selves" (Q.51:21) you would have tried to become introspective and look within your mind, but without the slightest chance of fathoming the dynamic nature of your brain's neurochemical underpinnings. You might have thought for a moment of the languages and dialects heard around you, or of the differing facial features, skin colours or cultural habits of other tribes and nations - all of which the book you have heard recited claims are signs of the greatness of God.

This book, the Holy Qur'an, was urging ordinary people to peek beyond what is visible and interrogate conventional wisdom. Initially, many refused to heed this invitation because it did not resonate with what they were used to. Some even ridiculed it (Q. 37:14). In hindsight, and perhaps even more so today, answering this reality-penetrating call would have essentially meant an act of faith. Thus, it is intriguing that the inductive and empirical thinking that paved the way for our modern-day scientific method started as an act of belief. This is well in the sense that, if the Creator is urging us to investigate and explore the surrounding environment, there should be something wondrous in it. The Ayah zeitgeist was born when, ultimately, many heeded the call to engage with reality through this new sign-based method (manhaj). It is well-known that inductive thinking was hitherto premature, if not completely unknown. Muslim scientists subsequently adopted and advanced it as an extensive tool for hunting for signs, patterns and trends in factual data that could be generalised into tentative explanations or broader theories. As a worldview, thinking through signs had many incentives: (a) a reality not to be denied, full of wonders to be explored, (b) a capable human talent not to be oppressed into conformity, and (c) an eternal reward, for 
every hour spent contemplating through signs (tafakkur) is loftier than years of ritualistic worship.

When I highlight the manhaj of thinking through signs, I am not introducing anything new. Thinking through signs is our default way of thinking, to the degree that everyone unwittingly expects to exchange meaning via a sign-based paradigm. References are made in the Qur'an to how people expect this standard of reasoning and exchange to work, including amongst sages (Q.19:10), common believers (Q.2:248), sceptics (Q.6:37, 2:118), as well as non-believers (Q.13:7, 7:106). Conventional discourses explain thinking through idealistic models, snapshots that, although descriptive and useful in limited domains, fail to capture the everyday habits and tendencies of human thinking. These have for too long theorised the objectives and the limits of our thinking in a very reductionist and mechanical way. That is precisely the reason why mainstream scientists often end up saying 'humans are irrational' when discussing typical consumer or religious behaviour. The positivist models cut to describe us do not fit. Thus, we end up cutting our toes trying to fit the theoretical shoe.

Thinking through signs takes into account intuition and belief as an inevitable part of the whole semiosis. The standard theory of thinking advanced by J. Baron resonates well with semiotic interpretations of the process of semiosis. To briefly paraphrase Baron, thinking is a purposive process; we think to make decisions, to form beliefs and to choose our personal goals. For Baron, thinking is about the search for goals, possibilities, and evidence, and then inferring or using evidence to determine how well these possibilities meet goals. When deciphering Baron's theories, I became aware of how belief is acknowledged to be part and parcel of our daily reasoning processes and rationality. Ideally, the search for possibilities and evidence should be infinitely exhaustive before we settle on any kind of conclusion. Nevertheless, in real life we do not always have unlimited time or the resources needed at hand. This is where pragmatism comes in. We typically make decisions based on this kind of thinking process, which is probabilistic in nature. In turn, our beliefs, emotions, personal experiences, memories, attention, intention and much more can bias our thinking processes. No wonder that modern therapeutical work aimed at curing certain behavioural patterns attempts to achieve this through modification of beliefs.

Personal beliefs and attitudes, selective attention, remembrance, emotions and much more are part and parcel of human rationality. This does not mean, however, that we must open the door to free-ranging superstitions and baseless symbolisms of all kinds. As Baron highlights, we are often biased in our thinking given that we selectively look for evidence to match and confirm our beliefs and we look for beliefs to explain the available evidence. This implies that, like life itself, thinking habits need continuous cultivation and care-taking, mandating an 
openness to new experiences. The Qur'anic injunction for sign-based thinking is a life-long pursuit, a fluctuating state of belief (iman) proportional to the scale and depth of one's experience of signs. With reality taking supremacy over one's subjective relativities, a believer is in a constant sign-search towards certainty (yaqin). With openness to signs as the very fiber of reality, sign-based thinking is transformative in the sense that it drives a believer to rise above self-serving bias, certain mental frameworks and cultural habits, as well as above current possibilities (Cf., Q.4:135, 5:8, 6:152, 11:49).

Thinking through signs involves the exertion of human cognitive powers. That implies consistent effort to maximise reality-checks and safeguard against any personal biases while searching for goals, possibilities and evidence. In this way, thinking through signs is more than a reliance upon isolated empirical facts. Visibility of facts without the gestalt and pragmatic sign-thinking paradigm will not go far. One needs to see the world as signs. Signs are beyond facts, not only from an in-depth perspective, but also from a reach perspective. Moreover, some people highlight how change can come only through sign-thinking, as only signs have the power of suggestibility to otherness. The more you zoom into a certain object under study, the more the complexity of its interior opens up, the more one understands that they are not individual units of facts but a complex structure of interrelated signs. Ideally, as in the Ayah zeitgeist, there should be no avoidance attitude towards empirical facts per se as reality is not to be feared. On occasions when there is seemingly contradictory empirical evidence, dedicated scientists have gone further with sign-based research and discovered something entirely new. The apparent contradiction was just a sign or a signal of a shortfall in our formulated beliefs and explanations.

The Qur'anic invitation to heed signs is still open and valid. However, as likely as 1,400 years ago, asking ordinary people today, including believers, to 'look around for signs' falls on deaf ears. Swept away as we are by both technological wonders and mundanity, prima facie ordinary people may not see much anyway. A creative pause may alert us to the necessity of pursuing this reality-penetration call. Prophet Jesus once said "I declare to you what ye eat, and what ye store in your houses" (Q.3:49), a statement that is reminiscent of the increasing surveillance possible due to prevailing global connectivity. Progression in human knowledge has made what was once miraculous seem ordinary. Reality is in a constant state of communicating from all sides and at all microscopic and macroscopic levels, a constant exchange of meaning for those "who use reason" (Q.30:24) or "care to understand" (Q.29:35). One thing about signs is that they are accessible to all (Q.54:2). A sign remains a sign regardless of relative human interpretation. By the same token, certain human interpretations are so rigid that they remain fixed regardless of what one comes to experience or 
witness. Qur'anic references are made to examples of such deep-rooted states of denial, so that at times people are ready to accept magic as reality but not reality as a sign! "But if they see a Sign, they turn away, and say, 'This is (but) transient magic"” (Q.54:2, 46:7). The challenge to infer God through accessible signs is not unique or exclusive. As mentioned, a more in-depth look at standard human thinking processes shows how we are cut to work as such, to infer from accessible signs higher-level objectives. Within the semiotic freedom we are endowed with, we often fail to take up this elevating intellectual task.

\section{Notes}

* Elma Berisha is an alumni of the International Islamic University Malaysia. She is a social researcher, psychologist by training, data scientist by profession, with a recent research interest in cognitive semiotics. In the past decade, Elma has worked with a wide spectrum of public institutions in Malaysia, including top universities, international organisations and professional bodies. Until 2015, Elma was the Regional Manager for Consumer Research in Asia Pacific, with Frost \& Sullivan. Her focus research area was on the evaluation of public perceptions in Malaysia and Singapore, primarily monitoring issues of public safety, corruption and urban development. Currently, Elma is attached to the Asian Institute of Finance, a Bank Negara think tank in Kuala Lumpur established to enhance human capital development. 